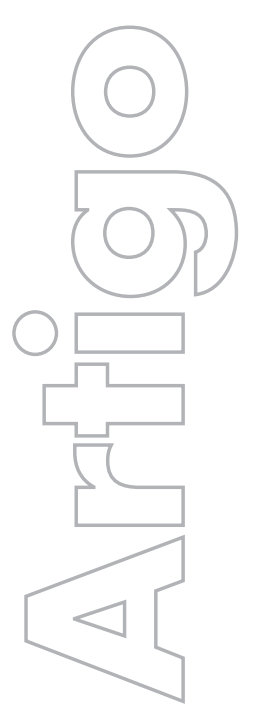

revista

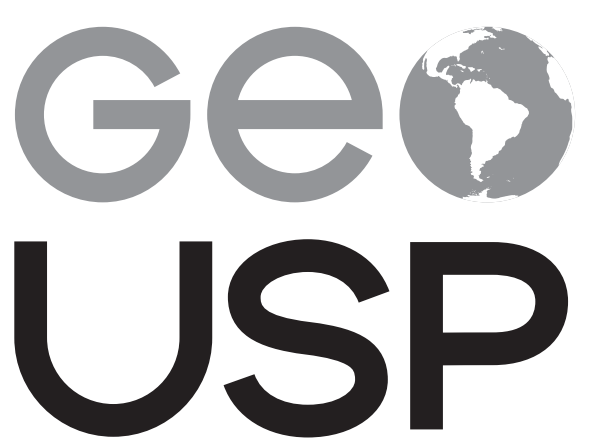

espaço e tempo

Volume $21 \cdot n^{\circ} 3$ (2017)

ISSN 2179-0892
Rosa Luxemburg e a expansão imanente do capitalismo: destruição, resistência e recriação dos territórios e das relações não capitalistas

Gustavo Francisco Teixeira Prieto USP

p. $812-829$

Como citar este artigo:

PRIETO, G. F.T. Rosa Luxemburg e a expansão imanente do capitalismo: destruição, resistência e recriação dos territórios e das relações não capitalistas. Geousp - Espaço e Tempo (Online), v. 21, n. 3, p. 812-829, dez. 2017. ISSN 2179-0892.

Disponível em: <http://www.revistas.usp.br/geousp/ article/view/99827 > . doi: 10.11606/issn.2179-0892. geousp.2017.99827.

\section{(c) $(1) \Theta$}

Este artigo está licenciado sob a Creative Commons Attribution 4.0 License. 


\title{
Rosa Luxemburg e a expansão imanente do capitalismo: destruição, resistência e recriação dos territórios e das relações não capitalistas
}

\section{Resumo}

objetivo deste artigo é analisar os escritos econômicos luxemburguianos, sobretudo o manuscrito Introdução à economia política, a partir da hipótese de que Rosa Luxemburg constrói uma tríade da formação das classes sociais capitalistas formulando uma interpretação não etapista e não evolucionista da história: destruição, resistência e recriação dos modos comunitários de produção e do campesinato são possibilidades abertas no processo de expansão do capitalismo sobre seus territórios. A análise da múltipla convivência de modos de produção e a noção de recriação de relações não capitalistas de produção a partir da reflexão de Luxemburg sobre os camponeses e o chamado comunismo primitivo explicitam a crítica ao progresso linear do espaço e da história e à barbárie moderna do capitalismo. A geografia agrária brasileira é tributária das interpretações luxemburguianas, e objetivamos também contribuir com a compreensão desse vínculo teórico e metodológico.

Palavras-chave: Rosa Luxemburg. Campesinato. Comunismo primitivo. Território. Relações não capitalistas de produção.

\section{Rosa Luxemburg and the immanent expansion of capitalism: destruction, resistance and recreation of territories and non-capitalist relations}

\begin{abstract}
The purpose of this paper is to analyze Rosa Luxembourg's economic writings, especially the manuscript entitled Introduction to Political Economy, from the assumption that Luxemburg builds a triad of capitalist social classes formation formulating an non-stagist and non-evolutionary interpretation of history: destruction, resistance and recreation of community modes of production and peasantry are possibilities opened on their territories by the capitalist expansion
\end{abstract}


process. The analysis of the multiple coexistence of modes of production and the notion of recreating non-capitalist production relations from Luxemburg's thinking about the peasants and the so-called primitive communism reveals her criticism towards the linear progress of space and history and the barbarian modern capitalism. The Brazilian Agrarian Geography is heir to Luxembourg's interpretations and so this paper also aims to contribute to the understanding of this theoretical and methodological bond.

Keywords: Rosa Luxemburg. Peasantry. Primitive communism. Territory. Non-capitalist production relations.

\section{Introdução}

Importantes intelectuais da questão agrária brasileira, tais como Martins' $(1996,1981)$ e Oliveira $^{2}$ (2004, 2010), argumentam que suas interpretações foram possíveis a partir da análise da obra de Rosa Luxemburg. Ao lado de Karl Marx e de outros autores marxistas como Theodor Shanin, Samir Amin, Kostas Vergopoulos e Eric Wolf, o pensamento luxemburguiano é um dos fundamentos, teórico e metodológico, para a produção da análise sobre o desenvolvimento contraditório do modo capitalista de produção, particularmente em sua etapa monopolista, que cria e recria relações não capitalistas de produção como, por exemplo, o campesinato e o latifúndio (Oliveira, 2010).

Na geografia agrária brasileira, especialmente os intelectuais que analisam a recriação de relações não capitalistas de produção inseridas contraditoriamente no modo capitalista de produção, verificam que o capital contraditoriamente se territorializa, expropriando parte da população camponesa e concentrando-a na cidade, utilizando sua força de trabalho na indústria e no trabalho assalariado no campo, mas também o próprio capital cria as condições para que as relações sociais camponesas se reproduzam fornecendo matérias-primas para as indústrias e viabilizando o consumo de bens industrializados no campo. Essa possibilidade desigual e combinada cria e recria a economia camponesa baseada em relações de trabalho familiar, e categoricamente define o campesinato como classe social inserida no capitalismo (classe em si e para si, na definição thompsoniana). A combinação entre economia e territórios capitalistas e não capitalistas - longe de ser uma debilidade do processo de acumulação do capital - pode ser analisada como a forma própria de se realizar a reprodução ampliada do capital, ou seja, a

\footnotetext{
"Num plano mais geral, reputo como importante, a partir da retomada da constatação de que o capital é um processo, desenvolvida por Marx, a observação de que o próprio capital engendra e reproduz relações não capitalistas de produção. [...] Fiz dessa constatação uma hipótese que abrangesse não apenas relações pré-capitalistas, mas o que o próprio Marx e, mais tarde, Rosa Luxemburg definiram como relações não capitalistas" (Martins, 1996, p. 3, grifo nosso).

2 "[...] faço parte de uma concepção teórica de compreensão do desenvolvimento capitalista no campo [...] que compreende que o estudo da agricultura deve ser feito levando em conta que o processo de desenvolvimento do modo capitalista de produção no território brasileiro é contraditório e combinado. Isso quer dizer que ao mesmo tempo em que esse movimento avança reproduzindo relações especificamente capitalistas, o capitalismo produz, também igual e contraditoriamente, relações camponesas de produção. Entre os mais importantes pensadores dessa corrente estão Rosa Luxemburg, Theodor Shanin, Samir Amin e Kostas Vergopoulos [...]" (Oliveira, 2004, p. 36, grifo nosso).
} 
unidade dialética entre trabalho assalariado, expansão do latifúndio e territorialização do monopólio capitalista com relações de produção e territórios não capitalistas: unidade camponesa, trabalho familiar camponês e resistências de modos comunitários de produção (Oliveira, 2010). Compreendemos que essa leitura apresenta como fundamento o pensamento de Rosa Luxemburg e é tributária das reflexões políticas e econômicas dos escritos luxemburguianos.

Nessa démarche torna-se fundamental retomar a obra de Rosa Luxemburg. O objetivo do presente artigo é analisar os escritos econômicos de Luxemburg, sobretudo sua Introdução à economia política ${ }^{3}$ (IEP), cotejando essa reflexão com momentos da Acumulação do capital (AKK). Nossa hipótese é que Rosa Luxemburg constrói na IEP uma tríade do processo de formação das classes sociais capitalistas: destruição, resistência e recriação dos modos comunitários de produção e do campesinato são possibilidades abertas pela expansão capitalista sobre seus territórios e relações sociais. A obra efetiva uma leitura original da classe camponesa e do assim chamado comunismo primitivo estabelecendo a noção de múltipla existência de diferentes modos de produção em todos os momentos da história e de relações não capitalistas inseridas contraditoriamente no capitalismo, o que supera [Aufhebung], em termos marxistas, a noção do desenvolvimento da sociedade em etapas pré-determinadas e o progresso linear do espaço e da história. Essa reflexão luxemburguiana é possível devido à centralidade da categoria de totalidade que a autora emprega ao longo de sua vasta e desafiadora produção intelectual. Vejamos, assim, esmiuçadamente essas considerações.

\section{A múltipla convivência de diferentes modos de produção e as relações não capitalistas de produção: Rosa Luxemburg muito além do etapismo}

A Introdução à economia política de Rosa Luxemburg, manuscrito inacabado publicado em 1925 por Paul Levi, advogado e executor testamentário de Luxemburg, é uma das obras mais polêmicas e de certo modo mais negligenciada dos escritos luxemburguianos. Löwy (1986) argumenta que a forma pouco habitual de abordar a Economia Política, enfatizando substancialmente o assim chamado comunismo primitivo, ou seja, o conjunto de relações sociais (prenhe de valores humanísticos) comunitários, coletivistas, comunais e o campesinato, que ocupa mais da metade da obra, é uma das principais razões pelas quais mesmo intelectuais críticos, militantes progressistas e revolucionários e até biógrafos de Rosa Luxemburg ignoram ou subestimam o trabalho.

Singer (2009) argumenta que Luxemburg era uma discípula que ousava criticar Marx. ${ }^{4}$ Firmemente ancorada na obra marxiana, a autora objetivava prolongar seu pensamento, sobretudo a partir da categoria de totalidade, concreta e estruturada, nos termos de Lukács

3 Desde 2008, está em andamento na França o projeto de edição das obras completas de Rosa Luxemburg a partir do coletivo Smolny - grupo sediado em Toulouse que tem a intenção de favorecer a reapropriação de ideias e contribuições essenciais da história política e social do movimento operário e dos movimentos sociais. O primeiro tomo que veio a público foi justamente a IEP. A fim de contribuir com a divulgação e atualização do pensamento luxemburguiano, as traduções da referida obra para o português foram propostas pelo autor do artigo a partir da edição em francês.

4 Luxemburg evidencia esse firme posicionamento antidogmático e ao mesmo tempo tributário de Marx: "a principal obra de Marx [O capital], assim como toda sua visão de mundo, não é nenhuma Bỉlia com verdades de última instância, acabadas e válidas para sempre, mas um manancial inesgotável de sugestões para levar adiante o trabalho intelectual, continuar pesquisando e lutando pela verdade" (Luxemburg, 2009b, p. 136). 
(2003) e Löwy (1978). Essa categoria possibilitou que Luxemburg compreendesse no processo histórico os movimentos contraditórios de produção e reprodução do capital, e assim vislumbrasse a dialética como motor de reflexão materialista da realidade.

Neusüss (1986), Martins (1996) e Singer (2009) verificaram que, na busca pela compreensão da expansão do capitalismo, Rosa Luxemburg descobre a múltipla convivência entre diferentes modos de produção, o que confrontou parte significativa do marxismo ortodoxo do século XX e do século XXI. Luxemburg argumenta:

No interior de cada país industrial europeu, a produção capitalista reprime constantemente a pequena produção camponesa e artesanal. Ao mesmo tempo, ela integra todos os países menos desenvolvidos da Europa, todos os países da América, da Ásia, da África, da Austrália, à economia mundial. Tal integração ocorre de duas maneiras: pelo comércio mundial e pelas conquistas coloniais. Ambos começaram juntos, desde a descoberta da América, no final do século XV, e se expandiram ao longo dos séculos posteriores. $\bigcirc$ apogeu desses processos ocorre, sobretudo, no século XIX e continua a se desenvolver. Comércio mundial e conquistas coloniais agem conjuntamente e colocam os países capitalistas industriais da Europa em contato com toda a sorte de formas de sociedade de outras partes do mundo, com formas de economia e de civilização mais antigas, economias escravagistas rurais, economias feudais e principalmente economias comunistas primitivas (2009a, p. 394, grifo nosso).

Além disso, em sua perspectiva - amplamente desenvolvida na Acumulação do capital -, o capital precisa de territórios não capitalistas - "algo fora de si mesmo" - para acumular, ou nos termos de Luxemburg (1985, p. 245), "a acumulação capitalista depende dos meios de produção que são produzidos de modo não capitalista".

Para a autora o objetivo e mola propulsora da produção capitalista não é a mais valia em qualquer quantidade, em uma única apropriação, "mas a obtenção ilimitada de mais valia, em um crescimento incessante em quantidades sempre maiores". Complementa que "é a produção de mais valia na sociedade capitalista que faz da reprodução das necessidades vitais desse [modo de produção] um moto contínuo" (Luxemburg, 1985, p. 12). Diante disso, sem a reprodução ampliada seria impensável, em especial, a troca e, com ela, o surgimento da sociedade de classes, inclusive o desenvolvimento histórico que resulta na forma econômica capitalista. Contudo, o capitalismo se realiza e se desenvolve historicamente (e contraditoriamente) em seu processo de acumulação permanente de capital, como fundamento imanente do processo de expansão capitalista, a partir de territórios não capitalistas.

Assim, Rosa Luxemburg separa a produção da reprodução do capital, colocando a acumulação originária não como um momento específico e determinado da geografia histórica do capitalismo, mas como um processo imanente e constitutivo da (re)produção contraditória do capital que se realiza como reprodução de relações não capitalistas dialeticamente articuladas ao capitalismo. Para que ocorra a produção do capital é fundamental a reprodução não capitalista, sendo necessário, para Rosa Luxemburg, analisar como se formam as classes sociais, ou seja, como ocorre a produção das classes sociais capitalistas. Do seio de 
sua teoria econômica, portanto, se desenvolve uma teoria política heterodoxa da expansão do capitalismo e a autora demonstra a impossibilidade da existência de uma matriz única para a formação da sociedade capitalista.

Luxemburg constata que há um desenvolvimento desigual do capitalismo que pode ser interpretado como uma diversidade de processos produtivos, nos quais as relações de produção especificamente capitalistas se desenvolveram mais em algumas regiões, fragmentos do território, ramos produtivos e setores econômicos do que em outros. Essa combinação entre relações capitalistas e relações não capitalistas de produção, longe de ser uma debilidade do processo de acumulação, pode ser analisada como a forma própria de se realizar a reprodução ampliada do capital, e compreendemos ser essa uma das principais potências das análises de Rosa Luxemburg. Por conseguinte, o mercado interno, conceituado como espaço econômico organizado segundo relações de produção capitalistas, tem necessidade permanente do mercado externo, espaço econômico organizado segundo relações de produção não capitalistas, necessidade fundada no fornecimento contínuo, por este último, de matérias-primas, força de trabalho e consumidores ao mercado interno. Em suma, a reprodução ampliada do capital necessita de relações de produção não capitalistas para se efetivar (Tavares Dos Santos, 1981; Martins, 1996).

capitalismo se caracteriza por uma extensão territorial, empreendida pela busca por mercados externos que se ampliou exponencialmente com as conquistas coloniais, e posteriormente imperialistas. É fundamental, nesse processo, a violência mediada pelo Estado capitalista sobre o comunismo dito primitivo, questão amplamente analisada na seção "As condições históricas da acumulação" d'A acumulação de capital e na Introdução à economia política. Luxemburg demonstra, com profundidade, a barbárie da expansão capitalista e a destruição de formas comunais de reprodução da vida de indígenas e camponeses:

A acumulação de capital como um todo, como processo histórico concreto, apresenta, pois, dois aspectos distintos. Um deles desenvolve-se nos centros produtivos da mais valia - nas fábricas, nas minas, nas propriedades agrícolas - e no mercado. Vista sob esse ângulo, a acumulação é um processo puramente econômico - cuja fase mais importante se realiza entre os capitalistas e os trabalhadores assalariados e cujas duas fases (no espaço fabril e no mercado) desenvolvem-se exclusivamente dentro dos limites estabelecidos pela troca de mercadorias e pela troca de equivalentes. Nesse nível, a paz, a propriedade e a igualdade reinam como formas e faz-se necessária a dialética apurada de uma análise científica para descobrir como por meio da acumulação o direito de propriedade se transforma em apropriação da propriedade alheia, a troca em exploração e a igualdade em dominação de classe. $\bigcirc$ outro aspecto da acumulação do capital é o que se verifica entre o capital e as formas de produção não capitalistas. Seu palco é o cenário mundial. Como métodos das políticas coloniais reinam o sistema de empréstimos internacionais, a política das esferas de influência e as guerras. Aí a violência aberta, a fraude, a repressão e o saque aparecem sem disfarces, dificultando a descoberta, sob esse emaranhado de atos de violência e provas de força, do desenho das leis severas do processo econômico. [...] [Assim] ambos os aspectos da reprodução do capital encontram-se interligados organicamente, resultando dessa união a trajetória histórica do capital (Luxemburg, 1985, p. 308-309). 
Assim, para além do argumento das formas e relações pré-capitalistas como remetentes de um passado distante, Luxemburg produz argumentos que focalizam as formas de resistência e recriação de relações sociais não capitalistas (Martins, 1996; Singer, 2009) inseridas dialeticamente no modo capitalista de produção como constitutivas e necessárias para o processo de reprodução do capital.

Rosa Luxemburg produz em seus escritos econômicos uma análise densa sobre o processo de formação das classes capitalistas ao analisar o campesinato e o que ela denomina comunismo primitivo, objetivando compreender o desenvolvimento do capitalismo a partir dos sujeitos que sofrem diretamente a violência da transformação das relações sociais, políticas, econômicas e territoriais no processo de expansão do capitalismo. A destruição da organização interna das sociedades não capitalistas é uma característica recorrente desse processo avassalador, mas Rosa Luxemburg percebe que há também estratégias de resistência e formas de recriação de relações sociais não capitalistas. A resistência se realiza por intermédio da luta pela manutenção da existência, isto é, em formas de enfrentamento direto contra processos de "proletarização" e "europeização" e a recriação se efetiva na permanência insubordinada e potencialmente anticapitalista dos sujeitos não capitalistas em seus territórios habitados ancestralmente, ocupados como forma de resistir e/ou retomados na luta. Assim, o campesinato se recria como classe social capitalista e os múltiplos modos comunitários de produção se reproduzem simultaneamente na sociedade capitalista, processos que se realizam com tensões, conflitos e resistências.

\section{Rosa Luxemburg entre camponeses e "comunismos primitivos"}

Rosa Luxemburg estabelece, em seus escritos econômicos, a questão da formação da propriedade privada, especialmente a formação da propriedade privada da terra, como uma centralidade na análise sobre a expansão das relações capitalistas em escala mundial. Nesse sentido, as relações sociais e econômicas do campesinato e seu processo de destruição, recriação e resistência atravessam a sua análise em diversos momentos.

Na IEP, ao analisar a economia camponesa, Rosa expõe uma reflexão ampla sobre alguns fundamentos das relações sociais do campesinato em sua constituição como classe social. $\bigcirc$ método de exposição luxemburguiano é original e revelador de sua relação com as classes sociais e povos oprimidos. A análise de Rosa Luxemburg visa compreender articuladamente as determinações da constituição social, política e econômica das classes e povos subalternizados, as suas lutas sociais e políticas e o processo de resistência ao desenvolvimento das relações especificamente capitalistas apresentados como verdadeira barbárie moderna e a recriação das relações sociais "pré-capitalistas" inseridas no capitalismo. Luxemburg, todavia, não negligencia o conjunto de limitações da estrutura social e da organização política tanto dos camponeses, quanto dos modos comunitários de produção.

Além disso, realiza também uma crítica mordaz à forma com que os economistas de inspiração burguesa (savants bourgeois nos termos da autora) retratam exclusivamente pela chave do economicismo os camponeses, mas também as populações indígenas, os pastores nômades e seminômades, os aborígenes, ou seja, as relações exteriores, alheias ou submetidas ao capitalismo, conceituando-os como relações não capitalistas. 
Em reveladora passagem da IEP, Luxemburg responde a possíveis questões que os economistas burgueses fariam aos camponeses, visando identificar suas relações econômicas de produção. Rosa Luxemburg delineia nesse processo com profundidade os fundamentos da constituição do campesinato como classe social.

Assim, inicialmente a autora reflete sobre a necessidade do trabalho e "os objetivos da economia" para os próprios camponeses, e afirma em nome do campesinato que

Para viver precisamos trabalhar, afinal as cotovias não caem assadas em nossas bocas. Se não trabalharmos, nós morreremos de fome. Nós trabalhamos então para nos manter, para nos alimentar, para nos vestir e para ter um teto sobre nossas cabeças (Luxemburg, 2009a, p. 148).

Ou seja, Rosa Luxemburg verifica a centralidade do trabalho como condição para a reprodução dos camponeses. $\bigcirc$ trabalho se realiza como mediação fundamental para a reprodução da vida camponesa, sendo a impossibilidade de reprodução da vida (fome e privações diversas) o horizonte negativo da impossibilidade da manutenção da família.

Outra questão que seria colocada pelos savants bourgeois refere-se à produção camponesa e aos sentidos do trabalho camponês. Transfigurada em camponesa, Luxemburg (2009a, p. 148-149) argumenta:

Nós produzimos o que necessitamos, o que toda e qualquer família camponesa precisa para viver. Cultivamos o trigo e o centeio, a aveia e a cevada, plantamos batatas e criamos, de acordo com as necessidades, vacas, ovelhas, galinhas e patos. No inverno, as mulheres fiam, e nós homens, com o auxílio do machado, da serra e do martelo reparamos a casa. Chame como quiser, "economia agrícola" ou "artesanal". Em todo caso, é preciso que façamos um pouco de tudo dentro de casa e no campo.

Rosa Luxemburg apresenta, assim, outra característica fundamental do campesinato: as relações diretas entre a produção camponesa de alimentos e a reprodução da família camponesa. A noção de "necessidade" se coloca como argumento central da economia camponesa, visto que a produção por "necessidade" do campesinato não se refere estritamente à produção da mercadoria capitalista como condição da mediação entre valor de uso e valor de troca.

A autora reflete também sobre a divisão sexual do trabalho. A participação do trabalho feminino em uma determinada comunidade camponesa é colocada em paralelo com outras experiências de indígenas e camponeses.

Os homens fazem evidentemente o que exige uma força masculina, as mulheres se ocupam da casa, das vacas e do galinheiro, as crianças ajudam aqui e acolá. Ou você acha que eu deveria enviar minha esposa para cortar lenha enquanto eu ordenho as vacas? ( $\bigcirc$ bom homem não sabe, mas acrescento por minha conta que, dentre muitos povos primitivos, por exemplo, entre certos índios do Brasil, é precisamente a mulher que vai a floresta coletar madeira, desenterrar raízes e colher os frutos, enquanto entre pastores na África e na Ásia, os homens não somente cuidam do gado como também o ordenham. Pode-se observar também 
ainda hoje na Dalmácia que as mulheres carregarem pesados fardos nas costas, enquanto que vigorosos homens andam ao lado de seus asnos, fumando cachimbo tranquilamente. Essa "divisão do trabalho" parece tão natural para eles, como parece natural ao nosso camponês cortar lenha enquanto sua esposa ordenha as vacas) (Luxemburg, 2009a, p. 149).

E sobre o que significa riqueza, Rosa Luxemburg aponta as bases de um processo de produção não capitalista mediado pelo trabalho camponês e a produção da riqueza relacionada diretamente à apropriação de terras:

E então, o que chamo de riqueza? Mas toda criança da comunidade sabe! É rico o camponês que tem um celeiro cheio, um estábulo preenchido, um imponente rebanho de ovelhas, um grande galinheiro; pobre é aquele que não tem farinha e que a água atravessa o teto quando chove. 'De que depende o aumento da minha riqueza?' Que boa pergunta?! Se eu tivesse um pedaço maior de terra boa, eu seria naturalmente mais rico, e se no verão, Deus nos livre, há uma tempestade de granizo, nós seremos pobres em 24 horas (Luxemburg, 2009a, p. 149).

Acerca da análise de Rosa Luxemburg sobre o campesinato é fundamental destacar que estão contidas na IEP as tensões entre o evolucionismo em etapas do desenvolvimento da história, traço marcante do marxismo da $2^{\text {a }}$ Internacional, e certamente também uma profunda e contundente crítica a esta ideologia do progresso linear (Löwy, 2000). A ideologia burguesa de caráter positivista da evolução da sociedade em etapas sucessivas tomou de assalto diversas correntes do marxismo (e dos movimentos revolucionários) na virada do século XIX para o século XX. A crença na inexorabilidade do socialismo como resultado lógico do desenvolvimento das forças produtivas permeou parte substancial dos escritos marxistas da $2^{\text {a }}$ Internacional. Além disso, havia o axioma da destruição completa das relações sociais "pré-capitalistas", que transformaria rapidamente boa parte da população mundial em proletários. Rosa Luxemburg apresenta traços desse evolucionismo nesta passagem:

Assim, um continente após o outro e em cada continente, um país após outro, uma raça após a outra passa inevitavelmente à dominação do capital. Milhões de pessoas são condenadas à proletarização, à escravidão, à uma existência incerta, em suma à pauperização. A instauração da economia capitalista mundial implica a expansão, cada vez maior, da miséria, de uma carga insuportável de trabalho e de uma insegurança crescente da existência sobre a superfície terrestre, os quais correspondem [diretamente] à concentração de capital. A economia capitalista mundial implica ainda que a humanidade seja subjugada a trabalhos cada vez mais penosos, além de incalculáveis males e privações, ela é entregue à degeneração física e moral para servir à acumulação do capital. $\bigcirc$ modo de produção capitalista apresenta assim a particularidade de que o consumo humano, que era o objetivo de todas as economias anteriores, agora não é mais que um meio para o objetivo do capital: a acumulação capitalista. $\bigcirc$ crescimento do capital aparece como o princípio e o fim, um fim em si e o sentido de toda a produção. $\bigcirc$ absurdo dessas 
relações só aparece na medida em que a produção capitalista torna-se mundial. A economia (capitalista) mundializada sujeita a humanidade ao jugo de um terrível poder social cego: o capital. $\bigcirc$ objetivo fundamental de toda forma social de produção: a relação da sociedade com o trabalho, a satisfação das necessidades, aparece assim completamente invertida, já que a produção para o lucro e não mais para o homem torna-se a lei sobre toda a terra e o subconsumo, a insegurança permanente do consumo e em determinados momentos o não consumo da maioria da humanidade torna-se a regra (Luxemburg, 2009a, p. 396-397).

Certamente o desenvolvimento espaço-temporal do capitalismo se realiza a partir de uma tendência de destruição das relações sociais, econômicas e políticas de modos de produção exteriores, alheios ou mesmo contraditórios à sua plena realização. Esse processo produz um efetivo desenvolvimento das forças produtivas e o assim chamado "progresso econômico". Rosa Luxemburg, tal como Marx em suas análises sobre a Índia e Marx e Engels em diversos momentos do Manifesto Comunista, evidenciam esse processo.

Entretanto, a expansão do capitalismo é contraditória, geograficamente desigual e historicamente combinada, e não se realiza em etapas pré-determinadas. As consequências sociais nefastas do "progresso capitalista" em escala mundial (Löwy, 1986, 2009) não são ocultadas no humanismo revolucionário de Rosa Luxemburg, tal como Marx compreendeu na expansão do capitalismo inglês na Irlanda, no capítulo XXXI d'O Capital e nos seus escritos tardios sobre a Rússia. A resistência ao processo de proletarização é uma marca fundamental do processo. A história dos decênios de guerras coloniais durante o século XIX, as revoltas contra a França, a Itália, a Inglaterra e a Alemanha na África, contra a França, a Inglaterra, a Holanda e os Estados Unidos na Ásia e contra França e Espanha na América é a história da longa e tenaz resistência realizada pelas sociedades indígenas à eliminação e proletarização pelo capital moderno, lutas nas quais o capital, inúmeras vezes, saiu vitorioso (Luxemburg, 2009a, p. 395-396).

Além disso, destacamos outro elemento contraditório do capital e que pode ser depreendido da leitura da IEP. Compreendemos que o motor das relações sociais do capitalismo é mais do que a produção de mercadorias: o objetivo central da produção do capital é a permanência acelerada e contínua da produção de mais valia e sua realização como lucro, se possível, sob a forma do lucro extraordinário. A aventura da produção capitalista é apenas um momento, fundamental certamente, para que se realize a transição entre D e D'. $\bigcirc$ capitalismo, então, como um modo de produção de mais valia se desenvolve não somente destruindo ou dissolvendo o que é exterior, mas sobretudo ressignificando e recriando formas, classes sociais e relações sociais trans-históricas a fim de sujeitá-las ao capital.

Analisando o campesinato, Luxemburg aponta brechas para verificarmos essa hipótese. Em sua reflexão sobre o campesinato europeu, sobretudo da Europa Ocidental, a autora constata a condição social camponesa e seu subjugo como classe no feudalismo aos senhores feudais. Ela observa que o campesinato feudal europeu era proprietário de terras e verifica as semelhanças e diferenças entre pequenos e grandes proprietários de terra no feudalismo. 
Tanto o pequeno camponês na sua propriedade quanto o grande monarca no seu domínio sabem exatamente o que querem obter com suas produções. E não é difícil de compreender: eles querem satisfazer as suas necessidades em alimentos, bebidas, vestimentas e outras fundamentais à reprodução da vida. A diferença é que o camponês dorme sobre a palha seca e o grande proprietário fundiário sobre um macio lençol, o camponês bebe cerveja ou hidromel e o grande proprietário vinhos finos. A diferença reside na quantidade e na qualidade dos bens produzidos. [...] existem diferenças no processo de trabalho: o camponês trabalha ele mesmo e com os membros de sua familia e ele detém o fruto de seu trabalho o quanto que possa fornecer seu acre de terra e sua parte de terra comunal, ou melhor - já que estamos falando do camponês medieval com taxas e corveia a pagar - na medida em que paga o senhor e a lgreja as obrigações feudais (Luxemburg, 2009a, p. 153-154).

Com o desenvolvimento do capitalismo o campesinato da Europa Ocidental tem terras a perder e o processo de acumulação originária se realiza com a dissolução e/ou destruição de suas relações intrínsecas com a terra. Isto é, a transformação da propriedade camponesa em propriedade privada capitalista é um momento fundamental no florescimento capitalista europeu. A instituição do modo capitalista de produção na Inglaterra, por exemplo, se realiza a partir de uma profunda revolução na agricultura com a formação do proletariado a partir do campesinato expropriado ou expulso de suas terras. A confiscação de bens da Igreja é outro elemento que coloca o campesinato em uma situação profundamente desfavorável.

Na Inglaterra, o novo modo de produção foi introduzido por uma revolução na agricultura. $O$ crescimento da indústria de lanifícios em Flandres criou uma grande demanda por lã e instou a nobreza feudal inglesa à transformação de grande parte das terras aráveis em pastagem para ovinos, expropriando os camponeses de suas terras. Uma massa de trabalhadores que nada possuía, tornados proletários, se encontra assim à disposição da nascente indústria capitalista. A Reforma segue a mesma direção, resultando no confisco dos bens da Igreja que foram em parte doados, em parte vendidos a baixíssimos preços à nobreza e à especuladores, e outra vez a população camponesa se viu igualmente [e] em grande parte expropriada. Os proprietários de manufaturas e os grandes proprietários capitalistas da terra encontram uma população pobre, proletarizada, que escapou das regulamentações feudais e das corporações e que após longo martírio de vida errante, duros trabalhos nas workhouses, cruéis perseguições da lei e da polícia, veem uma porta de saída na escravidão salarial ao serviço da nova classe de exploradores. As grandes revoluções técnicas, no interior das manufaturas, permitiram cada vez mais, ao lado ou no lugar do artesão qualificado, o emprego sem cessar do trabalhador assalariado sem qualificação (Luxemburg, 2009a, p. 168).

Na América Latina, entretanto, o processo se realiza de outra forma. Rosa Luxemburg evidenciou paralelos, complementariedades e algumas diferenças desse desenvolvimento desigual do capital. A autora argumenta que a conquista da América e a abertura de novas 
rotas de comércio para a África e para as Índias se relaciona diretamente com o processo de surgimento dos Estados burocratizados e centralizados europeus, inicialmente Portugal e Espanha e posteriormente França, Inglaterra, Holanda e Bélgica. No decorrer do processo de colonização europeia, a população nativa não teve direito à terra, exceto em determinados casos específicos de reduções e aldeamentos indígenas ou nas formas de encomiendas. $\bigcirc$ massacre de indígenas, o saque de matérias-primas e o roubo de terras são as bases fundamentais do processo de colonização. As formas de inserção dos autóctones foram o trabalho compulsório, a subordinação de suas relações sociais com a terra e o amplo processo de escravização. Analisando um conjunto de autores que produziram narrativas etnográficas e corográficas sobre a América Latina, Luxemburg cita o jurista e historiador espanhol Alonso de Zurita (1512-1585):

Não há um pedaço de terra, uma parcela sequer que não tenha sido declarada propriedade dos europeus, infringindo os interesses e direitos de propriedade dos indígenas que foram forçados a deixar seus territórios habitados desde tempos imemoriais (Zurita apud Luxemburg, 2009a, p. 275).

Ou seja, para manter seus modos comunitários de produção, as "comunidades primitivas" deveriam necessariamente migrar para fragmentos do território distantes dos interesses econômicos mais imediatos dos colonizadores europeus em uma condição de provisoriedade e ameaça constante, visto o caráter permanente do processo de expansão do capitalismo. Nesse sentido, os indígenas não têm reconhecido seu direito à terra, e Rosa Luxemburg percebeu esse processo.

Os escravos africanos também não se constituíram como proprietários de terra na América Latina. Amplamente importados para as Américas estes se realizam na economia colonial como renda capitalizada pelo fato de que o próprio trabalhador escravo entra no processo de produção como mercadoria. Sua condição de sujeito é brutalmente reduzida e coisificada.

$\bigcirc$ proprietário desejava extrair do seu escravo um rendimento econômico que era medido pelo lucro médio e este deveria lhe equivaler pelo menos ao dinheiro que lhe daria se fosse aplicado em outro negócio. $\bigcirc$ empreendimento colonial, para necessariamente ser lucrativo e sustentar essa forma de absorção de renda, deveria ser baseado na apropriação de vastas extensões de terra para mobilizar o trabalho escravo para produzir, atendendo às demandas da produção da metrópole e às formas de acumulação de capital assentadas no tráfico de escravos como motor dessa engrenagem de produção de capital (Martins, 1996). Ou seja, os escravos negros, somente quando conseguem fugir e encontrar quilombos, podem se constituir como camponeses, mas mesmo assim não eram detentores da propriedade da terra.

Mesmo com a experiência das encomiendas e dos aldeamentos indígenas não é possível afirmar que a formação do campesinato latino-americano advenha de uma condição de proprietário de terras, tal como o camponês de boa parte da Europa Ocidental. Além disso, o processo de proletarização das sociedades latino-americanas é experiência recente que se aprofunda a partir da década de 1950. Depreende-se assim que na América Latina os cam- 
poneses e os indígenas conquistam a terra, lutam para adquirir e/ou retomar a terra ou ter reconhecido seu direito consuetudinário à terra e resistem aos processos de expropriação nas fronteiras possíveis, onde não se desenvolveu plenamente o capitalismo.

Essa diferença entre o campesinato europeu e o campesinato latino-americano - que não é obviamente o objeto de estudo de Rosa Luxemburg e se desenvolve apenas a partir das pistas deixadas em momentos esporádicos da obra - nos parece fundamental visto que diversas lutas revolucionárias foram e são travadas na América Latina protagonizadas pelos camponeses em torno da luta pela terra, pela reforma e revolução que parte ou atravessa o campo, com o objetivo de transformação social, política e econômica da sociedade. Muitas dessas lutas camponesas não negligencia(va)m a figura política e os escritos de Rosa Luxemburg, sobretudo devido a sua teoria revolucionária do papel da ação revolucionária das massas e seu posicionamento antidogmático e não eurocêntrico.

Outro argumento central refere-se à constatação de Rosa Luxemburg de que o proletariado se constitui como classe social a partir da dissolução ou destruição das condições históricas de reprodução de parte do campesinato como classe social. Ou seja, Rosa Luxemburg observa que a formação da propriedade privada capitalista da terra gera um conjunto de empecilhos e impossibilidades para a reprodução do campesinato. Além disso, observa que a destruição das relações sociais de produção de populações autóctones auxilia no incremento da massa de trabalhadores que têm apenas a força de trabalho como propriedade. Rosa Luxemburg afirma, por exemplo, que as formas de luta e resistência não capitalistas podem se transformar em um "perigo" para a burguesia, visto que:

Mas, à luz destas lutas de classe brutais, a descoberta mais recente da investigação científica - o comunismo primitivo - revela seu aspecto perigoso. A burguesia, atingida no ponto nevrálgico de seus interesses de classe, fareja o elo obscuro entre as antigas tradições comunistas que nos países coloniais opõem, de modo tenaz, a resistência dos indígenas à busca incessante por lucro e ao progresso da "europeização" e o novo evangelho trazido pela impetuosidade revolucionária das massas proletárias nos velhos países capitalistas (Luxemburg, 2009a, p. 207-208).

Nesse trecho constata-se o argumento que enfatiza a resistência dos oprimidos como uma evidência relevante, verificando as relações e conexões entre as lutas dos proletários e das tradições comunitárias, coletivistas, comunais e camponesas dos países coloniais.

Rosa Luxemburg esboça em filigranas o argumento de que as vítimas da modernização capitalista e suas lutas e resistências pertencem à uma mesma tradição dos oprimidos, da qual o movimento operário é herdeiro. No início do século XX, Rosa posiciona-se de fato como uma marxista preocupada com a periferia do capitalismo e com os sujeitos periféricos em luta. Luxemburg, portanto, realiza na IEP um argumento herético e heterodoxo no marxismo, sobretudo no contexto da $2^{\text {a }}$ Internacional. Löwy $(1986,2008)$ captou com acuidade as pistas, no percurso de análise do pensamento luxemburguiano, de uma face ocultada da tradição dos oprimidos, verificando que há na IEP certa conexão entre as lutas e resistências anticolonialistas e anti-imperialistas como potencialmente lutas antica- 
pitalistas. Rosa Luxemburg possibilita a verificação da condição periférica como possível movimento de transformação, resistência e recriação e, quando organizado em massas, um movimento revolucionário. ${ }^{5}$

A tradição dos oprimidos advém, segundo Rosa Luxemburg, de um longo percurso: das lutas por liberdade dos escravos na Antiguidade, das quais a figura do escravo Spartakus se mantém emblemática; das lutas dos primeiros cristãos, sujeitos importantes por reivindicarem formas primitivas de comunismo a partir de seus mártires religiosos; dos camponeses alemães em guerra entre 1524 e 1525 e em certo milenarismo contra a opressão representado na figura de Thomas Münzer. Certamente as resistências dos camponeses e populações indígenas se inscrevem nessa linhagem.

Tanto como um ideal de uma outra ordem social baseada na igualdade e fraternidade entre os homens, como o ideal de uma sociedade comunista, o socialismo remonta a milhares de anos. Entre os primeiros apóstolos do cristianismo e entre várias seitas religiosas na Idade Média, durante a Guerra dos Camponeses, por exemplo, a ideia socialista não cessou de fluir como a expressão mais radical de revolta contra a ordem existente (Luxemburg, 2009a, p. 173-174).

Assim, constata-se que Rosa Luxemburg desenvolve uma interpretação que busca recuperar as tradições dos oprimidos e, com isso, ela realiza uma profunda reflexão sobre o assim chamado comunismo primitivo. Luxemburg não desconsidera as populações de fora da Europa Ocidental e de sua obra vertem discussões, por exemplo, sobre povos indígenas na América Latina, camponeses na Ásia, pastores na África, camponeses na Europa Oriental e populações nativas da Austrália.

Nesse sentido, a partir de uma perspectiva original e profundamente desafiadora, Rosa Luxemburg prolonga e articuladamente questiona a famosa resolução exposta no Manifesto Comunista: "a história das sociedades que existiram até nossos dias tem sido a história da luta de classes" (Marx; Engels, 2005). Luxemburg foi fortemente influenciada pelas pistas deixadas pelo próprio Manifesto e pelas análises de Engels no prefácio à edição alemã de 1890. Além disso constata-se o forte impacto na IEP da análise de Origem da família, da propriedade privada e do Estado (Engels, 1952) e a riqueza de interpretações acerca de um conjunto vastíssimo de relatos, livros, descrições etnográficas e corográficas de historiadores, etnólogos, antropólogos e homens de Estado como Georg Von Maurer, August von Haxthausen, Jean-Antoine Dubois, Maxime Kovalevski, Lewis Henry Morgan (principalmente), entre outros. Compreendemos que, a partir desse caleidoscópio de referências, Rosa Luxemburg propõe outro ponto de vista na interpretação das assim chamadas formas e relações pré-capitalistas, não podendo ser observada uma vertente única para a formação da sociedade e de suas relações sociais.

5 O século XX demonstrou a potência e a pertinência dessa argumentação. $\bigcirc$ papel do campesinato e dos indígenas nas revoluções socialistas e nas insurreições sociais é central e decisivo. Além disso, os grandes movimentos revolucionários no século XX ocorrem, sobretudo, na periferia do capitalismo: a Revolução Russa, em 1917, a Guerra Civil Espanhola, em 1936-1939; a Revolução Chinesa, em 1949; a Revolução Cubana, em 1959; a independência no Vietnã e a resistência vietcongue, os movimentos anticolonialistas e de independência na Argélia e no Congo; as lutas socialistas em Angola e Moçambique, as guerrilhas rurais na Nicarágua, em El Salvador e na Guatemala; as lutas por reforma agrária no Brasil a partir das Ligas Camponesas e depois pela Comissão Pastoral da Terra e pelo MST; o movimento dos seringueiros na Amazônia brasileira; o movimento zapatista em Chiapas, em 1994; e, no século XXI, a luta contra a privatização da água e do gás na Bolívia, a luta contra processos de privatização de terras na Índia e no Sri Lanka etc. 
Para Löwy (1986), o ponto central da análise de Rosa Luxemburg sobre as comunidades "pré-capitalistas" e o comunismo primitivo é a maneira crítica e original de conceber o desenvolvimento das formações sociais, que se fundamenta em uma veemente crítica à ideia forjada pela Economia Política burguesa da trans-historicidade do capitalismo, sobretudo da propriedade privada. Ou seja, Rosa Luxemburg analisa as diversas formas de propriedade e de relações com a terra e o território em diversos períodos anteriores à instituição do modo capitalista de produção, demonstrando que o capitalismo (e sua lógica) é um momento recente da história. A sociedade se desenvolveu durante milhares de anos a partir de relações sociais não mediatizadas pela mercadoria, pelo valor, pelo lucro, pela propriedade privada capitalista da terra e dos meios de produção, por formas indissociáveis de trabalho manual e trabalho intelectual, e mesmo pela não divisão em classes sociais.

Assim, o interesse de Luxemburg pelo comunismo primitivo se coloca como um prisma de análise comparativo entre essas sociedades e suas relações sociais (sua organização social, estruturas políticas e modo de produção) e o caráter irracional, reificado e anárquico do capitalismo que produz a oposição radical entre valor de uso e valor de troca. ${ }^{6} \mathrm{E}$, articuladamente, a diferenciação radical entre terra (e território) como condição de trabalho e reprodução da comunidade e terra como negócio de realização da mais valia a partir da propriedade capitalista da terra.

Löwy (1986) constatou que a busca de referências no passado dito primitivo apresenta como fundamento o devir da constituição do socialismo moderno. Rosa Luxemburg, nesse sentido, realizou um movimento progressivo-regressivo na história buscando compreender em diferentes sociedades as sementes de relações comunistas fundamentais para as lutas, e de certo modo, para a constituição do socialismo na contemporaneidade. E, também, apontou os equívocos, as contradições e os limites dessas organizações comunitárias do passado verificando suas opressões internas e elementos que propiciam desigualdade e exploração.

É fundamental, então, constatar que as relações comunais, coletivas e comunitárias (e também camponesas) com a terra aparecem como empecilhos para a constituição da plenitude das relações capitalistas, que o capital a partir de múltiplas formas desobstrui: expropriação direta ou sob o intermédio do Estado, guerras e extermínio em massa, endividamento, formas de arrendamento, instituição de vultosos tributos e impostos e estratégias fundiárias ilegais e/ou ilegítimas (grilagem, delimitações fundiárias, "confinamento" territorial) são as mais usuais; as formas de sujeição da produção agrária camponesa e indígena são as mais "modernas". Entretanto, a plenitude da expansão completa das relações capitalistas é uma tendência, ${ }^{7}$ não uma determinação, uma lei de bronze imutável e incontornável.

6 Mandel (1971, p. 2) capta com acuidade essa comparação de Luxemburg na IEP: "A explicação das diferenças fundamentais entre uma economia fundada sobre a produção de valores de uso, destinada a satisfazer as necessidades dos produtores, e uma economia fundada sobre a produção de mercadorias ocupa a maior parte da obra. Rosa Luxemburg desenvolve as diferentes lógicas desses dois sistemas econômicos. No primeiro, prevalece, inevitavelmente, a planificação, a organização consciente do trabalho; no segundo, constata-se a concorrência, a ausência de organização planificada, a anarquia. As formas transitórias de uma à outra são dissecadas com grande atenção, principalmente as relações entre o trabalho gratuito fornecido por uma parte da sociedade ao benefício exclusivo da outra".

7 Marx irá argumentar no Livro III d'O capital que tendência é um processo cuja realização absoluta passa a ser impedida, bloqueada, retardada e/ou enfraquecida por um conjunto de circunstâncias contrariantes. A tendência é uma noção que demonstra que o processo de produção, distribuição, circulação e consumo do capital e as formas de reprodução capitalista e distribuição da mais-valia não se realizam de forma absoluta, mas como possibilidade concreta. Essa noção auxilia na análise de uma teoria da história não determinista em Marx. A partir da noção de tendência, observamos que, para Marx, a história é um processo aberto, sem dúvida realizado pela expansão contínua do capitalismo, mas com possibilidades produzidas contraditoriamente por essa mesma expansão. 
Sobretudo na periferia do capitalismo, as relações especificamente capitalistas se instituem contraditoriamente, ora destruindo formas e relações sociais comunitárias e camponesas de produção, ora ressignificando essas relações. Mas, a resistência se constitui como mediação essencial nesse processo.

A nobre tradição do passado se conecta às aspirações revolucionárias do futuro, o círculo do conhecimento se fecha harmoniosamente e nessa perspectiva, o mundo atual da dominação de classe e da exploração, que pretendia ser o nec plus ultra da civilização, não é mais que uma minúscula etapa passageira da grande marcha da humanidade (Luxemburg, 2009a, p. 206).

De acordo com Luxemburg, o capitalismo é um interlúdio na história. Há, segundo a autora, profundas conexões entre as relações sociais não capitalistas no campo e suas tradições - humanismo, coletivismo e comunitarismo - e a ação revolucionária das massas proletárias na cidade. Na luta de classes, a história está em aberto: socialismo ou barbárie. O comunismo é a utopia real do devir da sociedade e representa trans-historicamente uma profunda tradição dos oprimidos. Assim, existem sociedades com profundos valores humanísticos, modos comunitários de produção e relações coletivas, comunais e camponesas com a terra realizando-se em todos os continentes, em todos os períodos da história com caraterísticas específicas de organização social, mas que apresentam semelhanças em seus fundamentos.

Consideramos que é possível depreender das análises sobre o comunismo primitivo a tríade dialética de processos que se desenvolvem no movimento de acumulação permanente do capital que recoloca/implode/supera a noção de formação pré-capitalista: destruição, resistência e recriação das "comunidades primitivas" podem ser constatadas nas interpretações luxemburguianas. Rosa Luxemburg ressalta o poder destrutivo do modo capitalista de produção em expansão, inclusive como condição para o seu desenvolvimento e se coloca ao lado das vítimas da barbárie do capital. Rosa Luxemburg critica veementemente os savants bourgeois que não concebem uma sociedade em que as relações sociais não sejam mediadas pela propriedade privada capitalista da terra. Assim, discordando frontalmente das interpretações de John Stuart Mill, por exemplo, Luxemburg (2009a, p. 198) argumenta:

Que a terra possa simplesmente pertencer aos camponeses que a cultivam desde muitos anos, que possa existir um país, uma grande sociedade civilizada, onde a terra não seja um meio de explorar o trabalho alheio, mas somente a base de existência para os que nela trabalham, é o que não entra absolutamente na cabeça do grande savant da burguesia inglesa.

Para além de uma análise do campesinato e dos modos comunitários de produção como relações sociais anteriores ao modo capitalista de produção, Rosa Luxemburg verifica sua "incômoda" permanência constantemente recriada e mediada pelas suas relações com a terra. E seu devir. 


\section{Considerações finais}

De acordo com Rosa Luxemburg, o desenvolvimento do capitalismo produz "a civilização atual com sua propriedade privada, sua dominação de classe, sua dominação masculina, seu Estado e seu casamento contratual", mas essa é "uma curta etapa passageira" (Luxemburg, 2009a, p. 205-206). Em termos luxemburguianos, a geopolítica da mundialização do capitalismo (e articuladamente da barbárie) enseja a necessidade urgente do socialismo. Essa necessidade se dá sobretudo pelo estado permanente de incerteza da existência que o capital universaliza. No entanto, essa universalização, longe de uniformizar os territórios, produz profundas desigualdades e bifurcações na história que se tornam concretamente oportunidades para a ação revolucionária das massas oprimidas, subordinadas, exploradas e expropriadas. Assim, a incerteza quanto ao futuro realiza no presente crítico as fagulhas potencialmente revolucionárias para a luta de classes e para a construção de um devir para além dos limites impostos pela ideologia capitalista.

Luxemburg assinala os caminhos da necessária implosão do modo capitalista de pensar, ao apontar a múltipla existência de diferentes modos de produção, ao demonstrar a recriação de relações não capitalistas de produção no capitalismo e ao analisar a formação das classes sociais capitalistas superando a matriz única de desenvolvimento da sociedade.

Assim, retomar e prolongar Rosa Luxemburg nos parece fundamental para compreender a expansão permanente do capitalismo, a unidade e o desenvolvimento geográfico desigual do capital e a centralidade das lutas anticoloniais, anti-imperialistas e anticapitalistas que partem da periferia e dos sujeitos periféricos. Além disso, a obra de Rosa Luxemburg permanece como fonte viva para compreender os desafios contemporâneos impostos pela sociedade mediada pelo capital e para melhor entender o materialismo dialético como método. A vasta obra produzida por Luxemburg ainda está por ser destrinchada, sobretudo pela geografia. A geografia agrária brasileira, tributária do pensamento luxemburguiano, tem como desafio retomar suas matrizes teóricas e metodológicas para permanentemente reconstruir os caminhos da práxis, e porta também a tarefa de contribuir com a atualização e a crítica da obra de Rosa Luxemburg.

\section{Referências}

ANDERSON, K. Marx aux antipodes: nations, ethnicité et société non occidentales. Paris: Syllepse, 2015.

ENGELS, F. L'origine de la famille, de la propriété privée et de l'État. Paris: Les Éditions Sociales, 1952.[1884]

FRÖLICH, P. Rosa Luxemburg, sa vie et son oeuvre. Paris: L'Harmattan, 1991[1939].

HARVEY, D. O novo imperialismo. São Paulo: Loyola, 2005[2003].

HUDIS, P. Accumulation, Imperialism, and Pre-Capitalist Formations. Luxemburg and Marx on the non-Western World. Socialist Studies/Études Socialistes, Chicago, v. 2, n. 6, p. 75-91, 2010.

JANOUVER, L. Rosa Luxemburg, histoire dans l'autre sens. In: LUXEMBURG, R. Introduction à l'économie politique. Marseille/Toulouse: Agone/Smolny, 2009[1925]. p. 11-100. Euvres completes, Tome I.) 
LOUREIRO, I. Rosa Luxemburg e os movimentos sociais contemporâneos: o caso do MST. Crítica Marxista, São Paulo, v. 26, p. 105-116, 2008.

Rosa Luxemburg: os dilemas da ação revolucionária. São Paulo: Unesp/Perseu Abramo, 2004.

LÖWY, M. A atualidade latino-americana de Rosa Luxemburgo. In: LOUREIRO, I. (Org.).

Socialismo ou barbárie: Rosa Luxemburgo no Brasil. São Paulo: Instituto Rosa Luxemburg Stiftung, 2009. p. 34-47.

. Marxismo e romantismo revolucionário. In: LÖWY, M. Romantismo e messianismo: ensaios sobre Lukács e Benjamin. São Paulo: Perspectiva, 2008[1980].

A dialética marxista do progresso. In: LÖWY, M; BENSAÏD, D. Marxismo, modernidade e utopia. São Paulo: Xamã, 2000. p. 77-83.

. Le communisme primitif dans les écrits économiques de Rosa Luxemburg. In: WEILL, C.; BADIA, G. Rosa Luxemburg aujourd' hui. Paris: PUV, 1986. p. 65-72.

Método dialético e teoria política. Rio de Janeiro: Paz e Terra, 1978.

. Le marxisme révolutionnaire de Rosa Luxemburg. Partisans, Paris, n. 45, dez.-jan, p. 60-66, 1969.

LUKÁCS, G. História e consciência de classe. São Paulo: Martins Fontes, 2003[1922].

LUXEMBURG, R. L'histoire de l'économie politique. In: LUXEMBURG, R. À l'école du socialisme. Marseille/Toulouse: Agone/Smolny, 2012a[1912]. p. 103-107. Fuvres complètes, Tome II.)

Sur l'esclavage. In: LUXEMBURG, R. À l'école du socialisme Marseille/Toulouse: Agone/Smolny, 2012b[1913]. p. 108-141. CEuvres complètes, Tome II.)

. A crise da social-democracia. In: LOUREIRO, I. (Org.). Rosa Luxemburgo: textos escolhidos. São Paulo: Unesp, 2011[1916]. p. 15-144. v. 2.

Introduction à 1'économie politique. Marseille/Toulouse: Agone/Smolny, 2009a[1925]. Cuvres complètes, Tome I.)

$\bigcirc$ segundo e o terceiro volumes d' $\bigcirc$ capital. Crítica Marxista, Campinas, n. 29, p. 135-143, 2009b[1917].

A acumulação de capital: contribuição ao estudo econômico do imperialismo. São Paulo: Nova Cultural, 1985[1913].

La révolution russe. Paris: François Maspero, 1964[1918].

MANDEL, E. Préface. In: LUXEMBURG, R. Introduction à 1'economie politique. Paris: Anthropos, 1971. p. 8-16.

MARTINS, J. S. O cativeiro da terra. São Paulo: Hucitec, 1996[1979].

Os camponeses e a política no Brasil: as lutas sociais no campo e seu lugar no processo político. Petrópolis: Vozes, 1981. 
MARX, K. O capital. São Paulo: Nova Cultural, 1985. v. I, II, III, IV, V. (Coleção Os Economistas.)

; ENGELS, F. Lutas de classes na Rússia. São Paulo: Boitempo, 2013.

Manifesto Comunista. São Paulo: Boitempo, 2005[1848].

NEUSÜSS, C. Patriarcat et organisation du parti. Rosa Luxemburg critique des idées de ses comilitants masculins. In: WEILL, C.; BADIA, G. Rosa Luxemburg aujourd'hui. Paris: PUV, 1986.

OLIVEIRA, A. U. A geografia agrária e as transformações territoriais no campo brasileiro. In: CARLOS, A. F. A. (Org). Novos caminhos da geografia. São Paulo: Contexto, 2010. p. 63-110.

Modo capitalista de produção, agricultura e reforma agrária. São Paulo: FFLCH/Labur, 2007.

Geografia agrária: perspectivas no início do século XXI. In: OLIVEIRA, A. U.; MAR-

QUES, M. I. M. (Org.). O campo no século XXI. São Paulo: Paz e Terra/Casa Amarela, 2004. p. 29-70.

SHANIN, T. E1 Marx tardío y la vía rusa: Marx y la periferia del capitalismo. Madrid: Editorial Revolución, 1990.

La clase incomoda: sociología política del campesinado en una sociedad en desarrollo (Rusia 1910-1925). Madrid: Alianza Editorial, 1983.

SIMONI DOS SANTOS, C. R. Territórios não capitalistas e reprodução do capital: o papel de Rosa Luxemburgo. Mercator, Fortaleza, v. 9, p. 27-38, 2010.

SINGER, P. Uma discípula de Marx que ousava criticar Marx. In: LOUREIRO, I. Socialismo ou barbárie: Rosa Luxemburgo no Brasil. São Paulo: Instituto Rosa Luxemburg Stiftung, 2009. p. 13-32.

TAVARES DOS SANTOS, J. V. A reprodução subordinada do campesinato. Ensaios FEE, Porto Alegre, v. 2, n. 2, p. 109-117, 1981.

THOMPSON, E. P. A formação da classe operária inglesa I: a árvore da liberdade. São Paulo: Paz e Terra, 1987.

WEILL, C. Rosa Luxemburg, ombre et lumière. Pantin: Le temps des cerises, 2008. 